\title{
Validation of HRDI MLT winds with meteor radars
}

\author{
F. Hasebe ${ }^{1}$, T. Tsuda ${ }^{2}$, T. Nakamura ${ }^{2}$, M. D. Burrage ${ }^{3}$ \\ ${ }^{1}$ Department of Environmental Sciences, Ibaraki University, Mito 310, Japan \\ 2 Radio Atmospheric Science Center, Kyoto University, Uji 611, Japan \\ 3 Space Physics Research Laboratory, University of Michigan, Ann Arbor, MI 48109-2143, USA
}

Received: 8 October 1996 / Revised: 12 May 1997/Accepted: 22 May 1997

\begin{abstract}
A validation study of the mesospheric and lower-thermospheric (MLT) wind velocities measured by the High-Resolution Doppler Imager (HRDI) on board the Upper-Atmosphere Research Satellite (UARS) has been carried out, comparing with observations by meteor radars located at Shigaraki, Japan and Jakarta, Indonesia. The accuracy of the HRDI winds relative to the meteor radars is obtained by a series of simultaneous wind measurements at the time of UARS overpasses. Statistical tests on the difference in the wind vectors observed by HRDI and the meteor radars are applied to determine whether the wind speed has been overestimated by HRDI (or underestimated by the MF radars) as previously noticed in HRDI vs. MF radar comparisons. The techniques employed are the conventional $t$-test applied to the mean values of the paired wind vector components as well as wind speeds, and two nonparametric tests suitable for testing the paired wind speed. The square-root transformation has been applied before the $t$-tests of the wind speed in order to fit the wind-speed distribution function to the normal distribution. The overall results show little evidence of overestimation by HRDI (underestimation by meteor radars) of wind velocities in the MLT region. Some exceptions are noticed, however, at the altitudes around $88 \mathrm{~km}$, where statistical differences occasionally reach a level of significance of 0.01 . The validation is extended to estimate the precision of the wind velocities by both HRDI and meteor radars. In the procedure, the structure function defined by the mean square difference of the observed anomalies is applied in the vertical direction for the profile data. This method assumes the isotropy and the homogeneity of variance for the physical quantity and the homogeneity of variance for the observational errors. The estimated precision is about $6 \mathrm{~m} \mathrm{~s}^{-1}$ for the Shigaraki meteor radar, $15 \mathrm{~m} \mathrm{~s}^{-1}$ for the Jakarta meteor radar, and $20 \mathrm{~m} \mathrm{~s}^{-1}$ for HRDI at
\end{abstract}

Correspondence to: F. Hasebe

(e-mail: hasebe@mito.ipc.ibaraki.ac.jp) 90-km altitude. These values can be used to confirm the statistical significance of the wind field obtained by averaging the observed winds.

\section{Introduction}

Our knowledge of atmospheric dynamics has recently expanded owing to the continuing development of new observational techniques, particularly those of remote sensing from satellites. Whenever a novel technique is proposed, it must be validated prior to scientific use by comparing the new results with established methods. Because the technique generally provides a new field of observations, the comparison is usually limited to only a part of the data set. Even if the comparison is restricted within some temporal and spatial domain, it may be considered valid by making some reasonable assumption, such as spatial homogeneity of the field, etc. Further confidence in the technique is gained by examining the consistency between the scientific results it provides and theoretical interpretations. Thus the validation process and scientific work interact to improve the understanding of the atmosphere.

This investigation is based on systematic comparisons between the results obtained by different observational techniques. The goal is to provide information on the quality of the observed data in two terms; the accuracy and the precision. The accuracy is the quantity representing how close the sample mean is to the true value. The precision is the measure of the magnitude of fluctuation of the observed values around the sample mean.

Because of the inherent difference in the observational techniques, there arise inevitable difficulties in any validation study. Specifically, the spatio-temporal scale of the measurement is different in every observational technique. Observations by radars achieve acceptable accuracy and precision by choosing appropriate inte- 
gration times, while satellite-borne sensors attain good results by observing large atmospheric volume and, in the case of HRDI, by applying spatial smoothing called sequential estimation (Rodgers, 1976; Ortland et al., 1995). It should be noted that the accuracy and the precision depend on the sampling condition and that simple comparison of these values from different observational techniques makes little sense. Depending on the characteristic scales, the observed values are not necessarily the same even if the observations are made at the same time at the same location. This point will be made clear by considering "the sampling volume in the sampling space" introduced later. In this study, any possible uncertainties that could arise from the finiteness of the sampling volume in the sampling space are called "observational errors."

The Upper-Atmosphere Research Satellite (UARS), launched on 12 September 1991, measures vertical profiles of temperature, concentrations of trace gasses, and horizontal wind velocities (Reber et al., 1993). Extensive efforts have been made to validate the measurements by using the correlative data provided by balloons, radars, etc. (e.g., Gille and Grose, 1994; Burrage et al., 1993). In the present study, we will try to extend the validation of the mesospheric and lowerthermospheric (MLT) wind velocities observed by the High-Resolution Doppler Imager (HRDI) on board UARS by using the meteor-radar measurements being performed at Shigaraki, Japan, and Jakarta, Indonesia.

HRDI observes wind velocities in the stratosphere, mesosphere, and lower thermosphere by measuring the Doppler shifts of $\mathrm{O}_{2}$ atmospheric absorption and emission bands (Abreu et al., 1989). Nighttime observations are restricted to the altitude of about $94 \mathrm{~km}$ to which the $\mathrm{O}_{2}$-band emission layer is confined (Burrage et al., 1994). HRDI has extended our capability of measuring global wind fields in the stratosphere, mesosphere, and lower thermosphere, where wind data were previously available only from radiosonde stations, radar and lidar sites and a few rocket facilities. Readers should refer to Hays et al. (1993) for the details of the instrument and the observational technique. Extensive efforts have already been made on the HRDI wind validations. The results are summarized in Ortland et al. (1996) for the stratospheric winds and in Burrage et al. (1996) for the MLT winds. Burrage et al. (1996) show that the HRDI winds agree well with those observed by radars, rockets, and the Wind Imaging Interferometer (WINDII), another wind sensor on UARS, except that the magnitude of the wind speed is smaller in MF radars than in HRDI. The reason for such a disagreement is still under investigation (see, e.g., Burrage et al., 1997). The purpose of the present study is to employ meteorradar data to confirm whether HRDI shows an overestimation of the wind speed relative to the meteor radars (Sect. 4). Such comparisons will provide an independent set of statistics useful for understanding the characteristics of the data. The other aim of the present study is to present a method for estimating the precision of the HRDI data by using the structure functions (Sect. 5). The usefulness of the results and the remaining problems requiring future investigation are discussed in Sect. 6 . We will begin with the description of the HRDI and correlative data sets (Sect. 2) and specifically define the characteristics of the observational errors (Sect. 3) important to the validation study.

\section{Data}

HRDI data have been archived by the HRDI Science Team at the University of Michigan, and are available at the Central Data Handling Facility located at NASA Goddard Space Flight Center. The wind data used in the present study are the Level-2 MLT winds retrieved by the version-10 algorithm on which the most comprehensive validation study so far by Burrage et al. (1996) is based. In order to maintain consistency with their comparisons against MF radars, the analyzed data in the present study are limited to those for the period before the shut down of HRDI on April 1995. See Burrage et al. (1997) for the performance of HRDI after the power recovery. As was mentioned in Sect. 1, the nighttime data are available only near $94-\mathrm{km}$ altitude. Because we need vertical profiles of wind velocities for estimating the precision, the nighttime data have not been used in the present study.

Meteor-radar winds are used as the correlative data sets. Two radars are employed, one the MU radar located at Shigaraki, Japan operable as a meteor radar (Nakamura et al., 1991) and the other at Jakarta, Indonesia (Tsuda et al., 1995). The specifications for these radars are summarized in Table 1. The MST (mesosphere stratosphere troposphere) mode operation of the MU radar, which uses the turbulent scatter echoes in the altitude range of about $60-90 \mathrm{~km}$ (Tsuda et al., 1990) thus giving the wind velocities at lower altitudes than the meteor mode, provides another important correlative data set. Unfortunately, however, the coincidences with HRDI observations have been found to be quite limited due to intermittent operation. The MST data are, therefore, used as a supplementary data set in the present study.

Table 1. Specifications for the meteor radars used in this study

\begin{tabular}{|c|c|c|}
\hline & MU Radar & Meteor Radar \\
\hline \multirow[t]{2}{*}{ location } & Shigaraki & Jakarta \\
\hline & $34.9^{\circ} \mathrm{N}, 136.1^{\circ} \mathrm{E}$ & $6.9^{\circ} \mathrm{S}, 107.6^{\circ} \mathrm{E}$ \\
\hline operation & intermittent & continuous \\
\hline frequency & $46.5 \mathrm{MHz}$ & $31.57 \mathrm{MHz}$ \\
\hline \multicolumn{3}{|l|}{ transmitter } \\
\hline peak power & $1 \mathrm{MW}$ & $10 \mathrm{~kW}$ \\
\hline average power & $50 \mathrm{~kW}$ & $500 \mathrm{~W}$ \\
\hline \multicolumn{2}{|l|}{ antenna } & $1.5 \mathrm{~km}$ \\
\hline transmitter & 475 crossed yagis & 5-element yagi \\
\hline receiver & 4 3-element crossed yagis & 3 5-element yagis \\
\hline direction & all sky & north \\
\hline meteors $\left(\right.$ day $\left.^{-1}\right)$ & $15000-20000$ & $1,000-2,000$ \\
\hline integration time & $60 \mathrm{~min}$ & $60 \mathrm{~min}$ \\
\hline operation & Aug 92-Nov 95 & Nov 92-Dec 94 \\
\hline coincidences & 14 & 65 \\
\hline
\end{tabular}




\section{Characteristics of observational errors}

Accuracy and precision are the fundamental quantities that characterize the quality of observational data. The former is defined as the magnitude of the difference (or the mean bias) between the true value and the limit of the ensemble mean value of samples reached by repeated observations under the same atmospheric conditions. The latter represents the magnitude of fluctuations (such as the variance) of the observed values around the sample mean. The accuracy of the HRDI wind measurements has been studied extensively by the instrument provider (e.g., Burrage et al., 1996), while less attention has been paid to the precision. One of the objectives of our study is to present a simple statistical method to quantify the precision of the observed data provided in the form of profiles.

The factors that control the precision of measurements will include the observational conditions such as solar zenith angle, view angle, and instrument temperature. The precision will also depend on the geographical and meteorological conditions such as season and surface albedo. Another source of perturbation will be the data handling procedures, including the length of the time integration and spatial scale of the smoothing.

The difficulty that is common in every validation study is that the spatio-temporal scale of the measurement is different for every observational technique. For example, data obtained by the satellite in a single line-of-sight direction may be taken within a fraction of a second. On the other hand, the winds estimated by radars and lidars are some mean values integrated for several minutes to as long as a few hours. The sampling volume will depend on the spatial scale of the atmospheric field that is observable from the instrument. The situation is schematically illustrated in Fig. 1. Here the temporal scale is defined as the time-interval that cannot be resolved by the observational technique. The observed quantities are some mean state of the atmosphere during this time-period. Thus, for HRDI it is chosen as the time-interval between forward- and backward-view scans that measure the same atmospheric volume, while for the radars it is

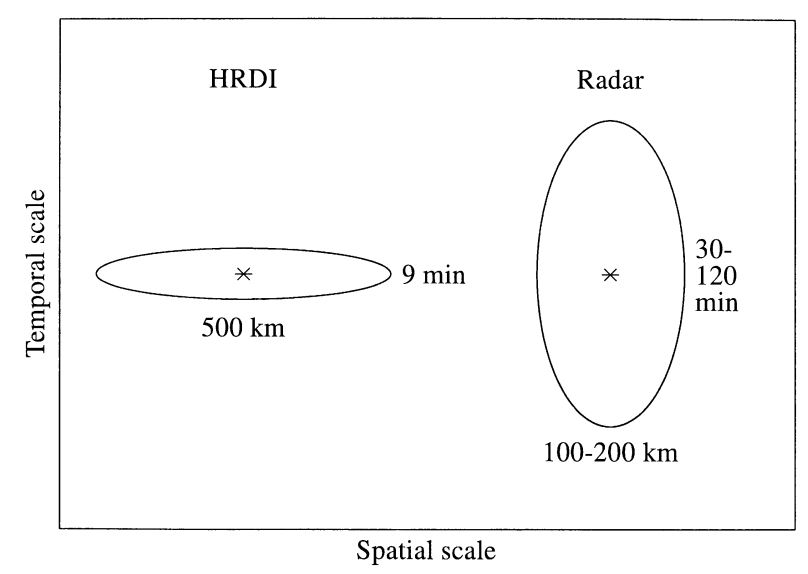

Fig. 1. Sampling volumes of typical observations in the spatiotemporal sampling space simply the integration time. Similarly, the spatial scale is taken as the horizontal extent of the atmospheric volume which is assumed to be homogeneous during sampling. It is thus a measure of the minimum atmospheric horizontal scale that the observational technique can resolve. For HRDI, it may be represented by the horizontal extent of the atmosphere seen by a tangential view of the telescope. Similarly, we adopt the horizontal width of the beam for radars. These scales determine the observational resolution of the dynamical field which is governed by the composite of the mean field and the wave activities such as those by gravity, tidal, and planetary waves, each of which may be characterized by the wind velocity of a similar order of magnitude.

An observation takes a sample from this spatiotemporal sampling space, assuming that the sample represents the physical quantity at a point (infinitesimal volume) in the sampling space. Validation involves comparing two sets of quantities obtained by different techniques taken at the same "point" in the sampling space. Because of the difference in the sampling volume in spatio-temporal space, however, the observed values are not necessarily the same even if the observations are made at the same time at the same location. For example, wind profiles observed by radars are sometimes dominated by gravity-wave components, while those by HRDI are unable to resolve such components. Because of the small horizontal scale of gravity waves, this situation can occur even in the comparison between radar winds separated by only several hundred kilometers, as noticed by Igarashi et al. (1996). These authors find that the tidal signature observed by the MU radar is perturbed by gravity-wave activity only for the meridional component, suggesting the north-to-south passage of gravity waves over the station. Considering the horizontal resolution, gravity waves of this kind will not be captured by HRDI. In such cases, HRDI winds could significantly deviate from the radar winds, reflecting the characteristics of the observational technique. The term "observational error" is used to describe any possible uncertainties that could arise from the finiteness of the sampling volume in the sampling space; it is neither restricted to the "error" that may come from the instrumental malfunctions, nor limited to the geophysical noise. Here we denote this error as $\varepsilon_{i}$ and $\zeta_{i, n}$ for the radar and HRDI wind component, respectively.

$$
\begin{cases}\text { radar data } & : \hat{f}_{i}=f_{i}+\varepsilon_{i} \\ \text { HRDI raw data } & : \hat{g}_{i, n}=g_{i, n}+\zeta_{i, n} \\ \text { HRDI processed data } & : \hat{h}_{i}=h_{i}+\eta_{i},\end{cases}
$$

where $\hat{f}_{i}, \hat{g}_{i, n}$, and $\hat{h}_{i}$ refer to the observed values, and $f_{i}$, $g_{i, n}$, and $h_{i}$, represent true values. $\varepsilon_{i}, \zeta_{i, n}$, and $\eta_{i}$ are observational errors, where $i$ refers to the altitude number, and $n$ is the scan number of HRDI raw data relative to that of processed data.

The purpose of our study is to derive the accuracy of HRDI winds relative to the meteor radars (Sect. 4) and to estimate the precision for both of these observational 
techniques (Sect. 5). First we divide the error into two parts, the mean bias and the deviation from it denoted by () and ()$^{\prime}$, respectively

$\varepsilon_{i}=\overline{\varepsilon_{i}}+\varepsilon_{i}^{\prime}, \quad \zeta_{i, n}=\overline{\zeta_{i, n}}+\zeta_{i, n}^{\prime}$.

We begin the procedure with the assumption that these errors are random, with a possible mean bias for both radar and HRDI wind observations. Here the random errors are those errors that are not correlated with both the true values of the observed quantity (Eq. 3) and the observational errors at different locations (Eq. 4):

$\overline{f_{i}^{\prime} \varepsilon_{j}^{\prime}}=\overline{g_{i, n}^{\prime} \varepsilon_{j}^{\prime}}=0, \quad \overline{f_{i}^{\prime} \zeta_{j, n}^{\prime}}=\overline{g_{i, m}^{\prime} \zeta_{j, n}^{\prime}}=0$

and

$\overline{\varepsilon_{i}^{\prime} \varepsilon_{j}^{\prime}}=\sigma_{f}^{2} \delta_{i j}, \quad \overline{\zeta_{i, m}^{\prime} \zeta_{j, n}^{\prime}}=\tau_{|i-j|} \delta_{m n}, \quad \overline{\varepsilon_{i}^{\prime} \zeta_{j, n}^{\prime}}=0$,

where $i$ and $j$ refer to the altitude number and $m$ and $n$ refer to the scan number of HRDI raw data. Here the variance of the random observational errors for radars is assumed to be homogeneous with respect to altitude and to take the value $\sigma_{f}^{2}$. The covariance of random observational errors for a HRDI wind profile is simply assumed to be a function of the magnitude of the altitude difference, $|i-j|$, and is denoted by $\tau_{|i-j|} ; \delta_{i j}$ and $\delta_{m n}$ are Kronecker's delta. Note that nonzero correlations expressed by $\tau$ can arise from the overlap of the weighting functions in the retrieval (e.g., Baily and Gille, 1986) associated with the limb viewing geometry of the instrument. Because the observational errors $\varepsilon_{i}$ and $\zeta_{i, n}$ cannot be free from geophysical noise, there could arise mutual correlations between the observational errors and the observed quantities (e.g., $\overline{f_{i}^{\prime} \varepsilon_{j}^{\prime}} \neq 0$ ) and between the observational errors themselves at different altitudes (e.g., $\overline{\varepsilon_{i}^{\prime} \varepsilon_{j}^{\prime}} \neq 0$ ) if some specific phenomenon dominates the variabilities during the whole span of the validation period. However, if the wind field is affected by a variety of phenomena (such as many kinds of gravity waves, tides, and planetary waves) that have different characteristics in magnitude and phase relationship between altitudes, we may regard the correlations as negligible. In this case, we may safely assume that the observational errors are random. We have no definite reasoning for the validity of this assumption, but we may begin our procedure by simply assuming that the observational errors (including the geophysical variabilities) are random.

HRDI winds are calculated from the raw data with a weighted average provided by sequential estimation (Rodgers, 1976; Ortland et al., 1995). In short, a physical quantity such as the wind-velocity component at an altitude $i$ of some specific location $\left(\hat{h}_{i}\right)$ is estimated as an average of the raw data at different locations and altitudes $\left(\hat{g}_{i+k, l}\right)$ :

$\hat{h}_{i}=\sum_{k, l} w_{k, l} \hat{g}_{i+k, l}$

and

$h_{i}=\sum_{k, l} w_{k, l} g_{i+k, l}, \quad \eta_{i}=\sum_{k, l} w_{k, l} \zeta_{i+k, l}$, where the weight for the raw data at the altitude $i+k$ and the location $l\left(\hat{g}_{i+k, l}\right)$ is denoted by $w_{k, l}$. This controls the degree of smoothing applied to the wind profiles. When the technique employs a relatively weak constraint, spurious oscillations appear in HRDI wind profiles, while if the constraint is too strong it suppresses the geophysical signals (see, e.g., Burrage et al., 1993, 1996). With the assumptions expressed by Eqs. 3 and 4, the statistics of HRDI processed data are obtained:

$$
\begin{aligned}
\overline{f_{i}^{\prime} \eta_{j}^{\prime}} & =\overline{g_{i, n}^{\prime} \eta_{j}^{\prime}}=\overline{h_{i}^{\prime} \eta_{j}^{\prime}}=\overline{h_{i}^{\prime} \bar{\varepsilon}_{j}^{\prime}}=\overline{h_{i}^{\prime} \zeta_{j, n}^{\prime}}=0, \\
\overline{\eta_{i}^{\prime} \eta_{j}^{\prime}} & =\overline{\sum_{k, l} w_{k, l} \zeta_{i+k, l}^{\prime} \cdot \sum_{m, n} w_{m, n} \zeta_{j+m, n}^{\prime}} \\
& =\sum_{k, m ; l} w_{k, l} w_{m, l} \overline{\zeta_{i+k, l}^{\prime} l_{j+m, l}^{\prime}} \\
& =\sum_{k, m ; l} w_{k, l} w_{m, l} \tau_{|(i+k)-(j+m)|},
\end{aligned}
$$

and

$\overline{\varepsilon_{i}^{\prime} \eta_{j}^{\prime}}=\sum_{k, l} w_{k, l} \overline{\varepsilon_{i}^{\prime} \zeta_{j+k, l}^{\prime}}=\sum_{k, l} w_{k, l} \overline{\varepsilon_{i}^{\prime} \zeta_{j+k, l}^{\prime}}=0$.

\section{Estimation of the accuracy relative to the meteor radars}

As mentioned in Sect. 2, most of the comparisons between HRDI and radar winds have been performed with MF radars (e.g., Burrage et al., 1996). One of the most serious discrepancies between HRDI and MF radar winds noticed in these studies is the difference in the derived wind speeds. Based on extensive validation studies, Burrage et al. (1996) found that there is a consistent magnitude discrepancy between HRDI and MF radar winds for all altitudes and both zonal and meridional directions at Christmas Island, Hawaii, and Saskatoon, and that such a discrepancy occurs only at altitudes above $85 \mathrm{~km}$ for the Urbana and Adelaide MF radars. These characteristics lead the authors to decompose the wind vectors into the speed and the direction rather than the velocity components; see Burrage et al. (1996, 1997) for detailed discussions. In the present analysis, we will examine wind velocity components of HRDI and meteor radars briefly and then investigate the wind speed in more detail. The present validation study using meteor radars provides an independent set of statistics.

Examples of the wind profiles observed almost simultaneously by HRDI and the meteor radars are shown in Fig. 2. No filtering has been applied to the radar profiles, and the error bars are derived from the standard deviation of the wind velocity components obtained by several to a few tens of meteor echo measurements made during $1 \mathrm{~h}$. In most cases, we can see very good agreement between the two independent observations. Although within the limit of uncertainties, it is interesting to see that the radar profile appears to oscillate around the HRDI profile exhibiting smaller vertical scale variations due possibly to gravity waves. Such features are consistent with the notion that the 

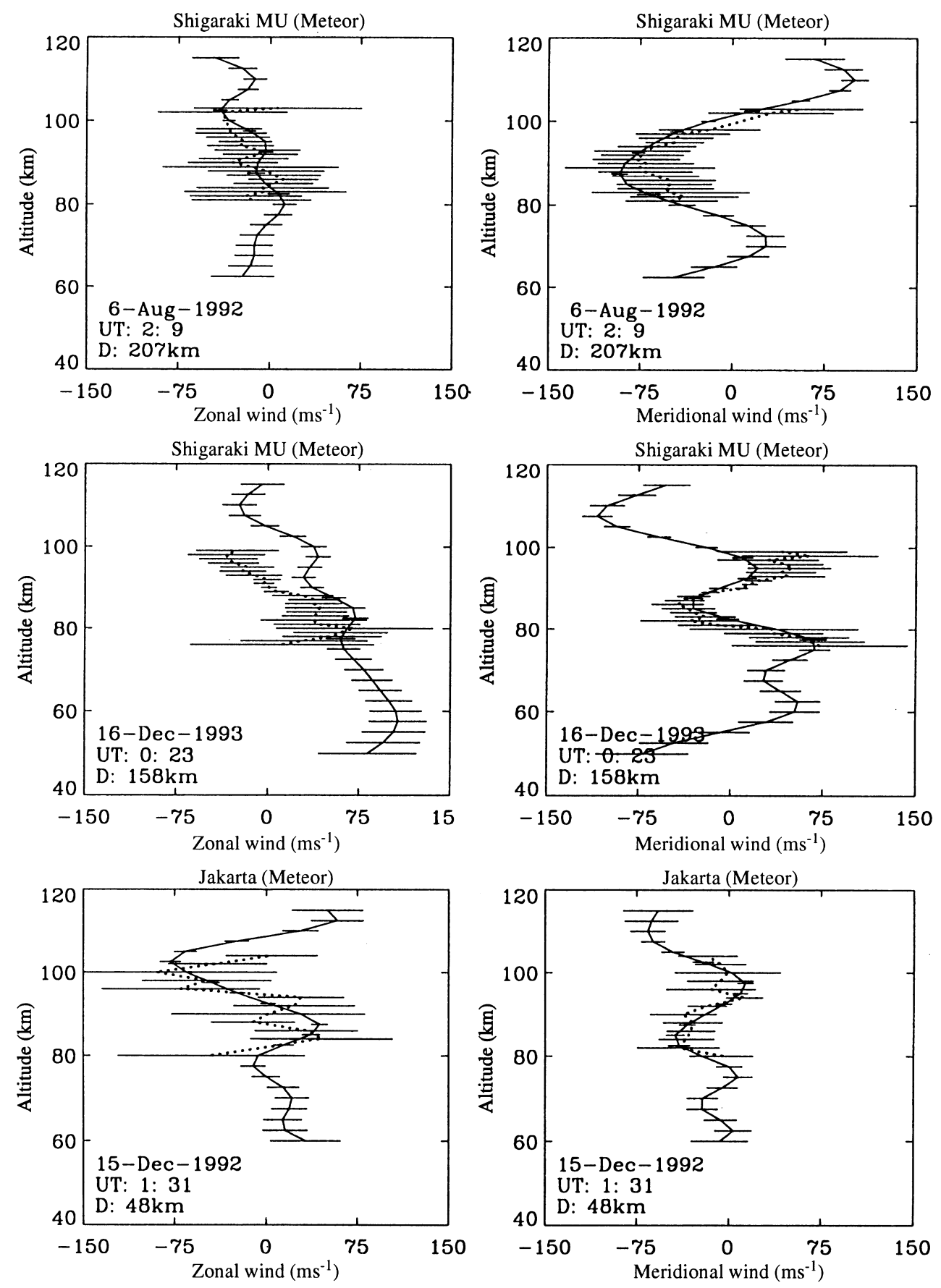

Fig. 2. Examples of simultaneous wind observations by HRDI (solid) and meteor radars (broken). Top and middle: Shigaraki MU radar meteor mode operation $\left(34.9^{\circ} \mathrm{N}\right.$, $\left.136.1^{\circ} \mathrm{E}\right)$. Bottom: Jakarta meteor radar $\left(6.9^{\circ} \mathrm{S}, 107.6^{\circ} \mathrm{E}\right)$

vertical resolution is poorer in HRDI than in the radar due to the sequential estimation of HRDI winds. In some cases, however, apparent biases are found between the two (zonal wind of the middle panel). The purpose of the present study is to quantify the degree of agreement between HRDI and the meteor-radar wind observations.

Scatter plots of the wind velocity components are shown in Fig. 3. Here the altitude range is limited to between 70 and $100 \mathrm{~km}$, to exclude less reliable data having large error bars. In contrast to the case of HRDI vs. MF radar comparisons (e.g., Fig. 11 in Burrage et al., 1996), there appears no indication of the overestimation by HRDI (underestimation by radars) of the wind speed. The comparison between HRDI and radar wind velocity components are extended in Fig. 4 which illustrates the vertical profiles of the ensemble mean wind velocity components simultaneously observed by HRDI (crosses) and radars (pluses). Here HRDI wind velocities $(2.5-\mathrm{km}$ vertical resolution) are linearly interpolated to the radar observation altitudes. Horizontal bars are $99 \%$ confidence intervals of the population mean values. The overlap of these bars indicates that the ensemble mean wind velocities estimated by HRDI and the radars agree with each other within the specified statistical uncertainties. However, there appears to be a tendency for the zonal wind measured by HRDI to be larger than that of the radars at around $90 \mathrm{~km}$ where the 

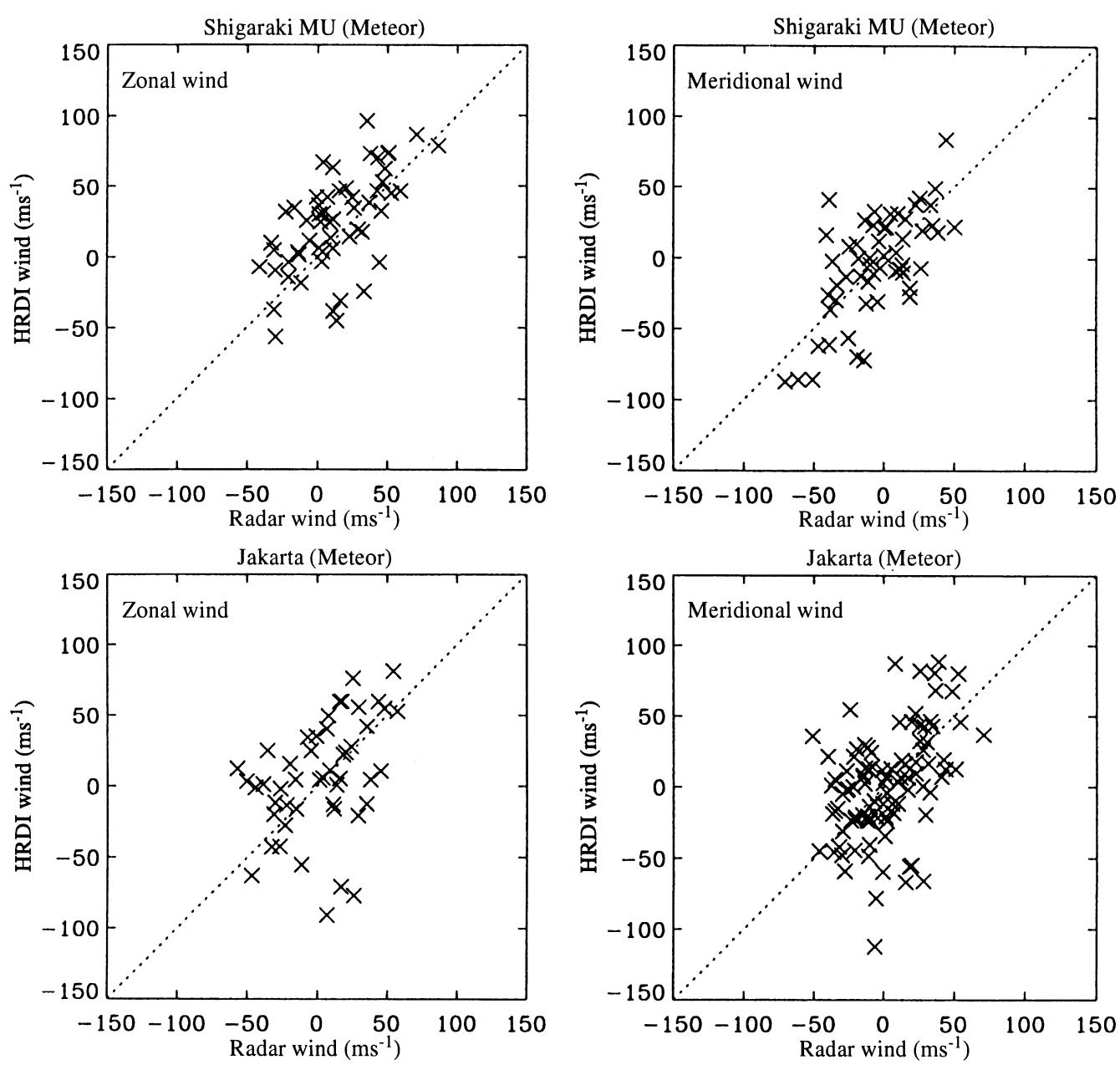

Fig. 3. Scatter plots of the wind velocity components observed by HRDI and meteor radars in the altitude range of 70 to $100 \mathrm{~km}$. Broken lines are references for equal velocities by two methods ensemble mean HRDI wind velocities show a maximum with respect to altitude. This is especially noticeable for the Jakarta meteor radar, where the ensemble mean zonal winds derived by HRDI (crosses) do not fall within the confidence intervals (horizontal bars) statistically estimated from the radar observations. This may be due to the less reliable zonal wind estimates resulting from the northward orientation of the Jakarta radar beam (Table 1).

Aside from the horizontal anisotropy of radars, there is no reason to discriminate between the zonal and meridional direction for HRDI because the wind vectors are derived from two line-of-sight wind velocity components which are not fixed to the earth but are directed at $45^{\circ}$ and $135^{\circ}$ in azimuth relative to the satellite track. In order to quantify the possible overestimation by HRDI (underestimation by MF radars) of the wind speed, Burrage et al. (1996) decomposed the wind velocities into the wind speed and the wind direction, and examined the median of the wind-speed ratio. Similar procedures are followed in the present study using the meteor winds. Fig. 5 shows the histogram of the speed ratio (HRDI/radar) and the direction difference (HRDI - radar) for meteor radars. The figure also includes results using the MST mode operation of the MU radar. The altitude coverage of the MST radar is restricted to a lower altitude, so that only the data from
70 to $75 \mathrm{~km}$ are used. Due to the asymmetry of the windspeed distribution, the median rather than the mean value is the more important statistical quantity. We can see that the median of the speed ratio (HRDI/radar) is close to 1 for the Shigaraki MU radar both in the meteor mode (1.379) and MST mode (1.037) and for the Jakarta meteor radar (1.051). The median of the direction difference (HRDI - radar) is almost $0^{\circ}$ for the three cases.

The vertical profiles of the median of the wind-speed ratio is shown in Fig. 6. The data are plotted only for the altitudes where the number of wind-speed pairs at that altitude is at least 9. The median is larger than 1 at around $87 \mathrm{~km}$ for the Shigaraki MU radar (meteor mode). For the Jakarta meteor radar, the median may deviate from 1 above $100 \mathrm{~km}$. It is necessary to perform statistical tests in order to make any conclusive statement on the significance of these features.

Examples of the wind-speed distributions of our sample are shown in the upper panels of Fig. 7 obtained from HRDI and Shigaraki MU radar (meteor mode) observations. The curved solid lines superposed on the distributions are the normal distribution functions having the same mean and variance as the observations. The tails on the right-hand side of the distributions are longer than expected from a normal distribution. The goodness of fit in the normal distribution is examined by 

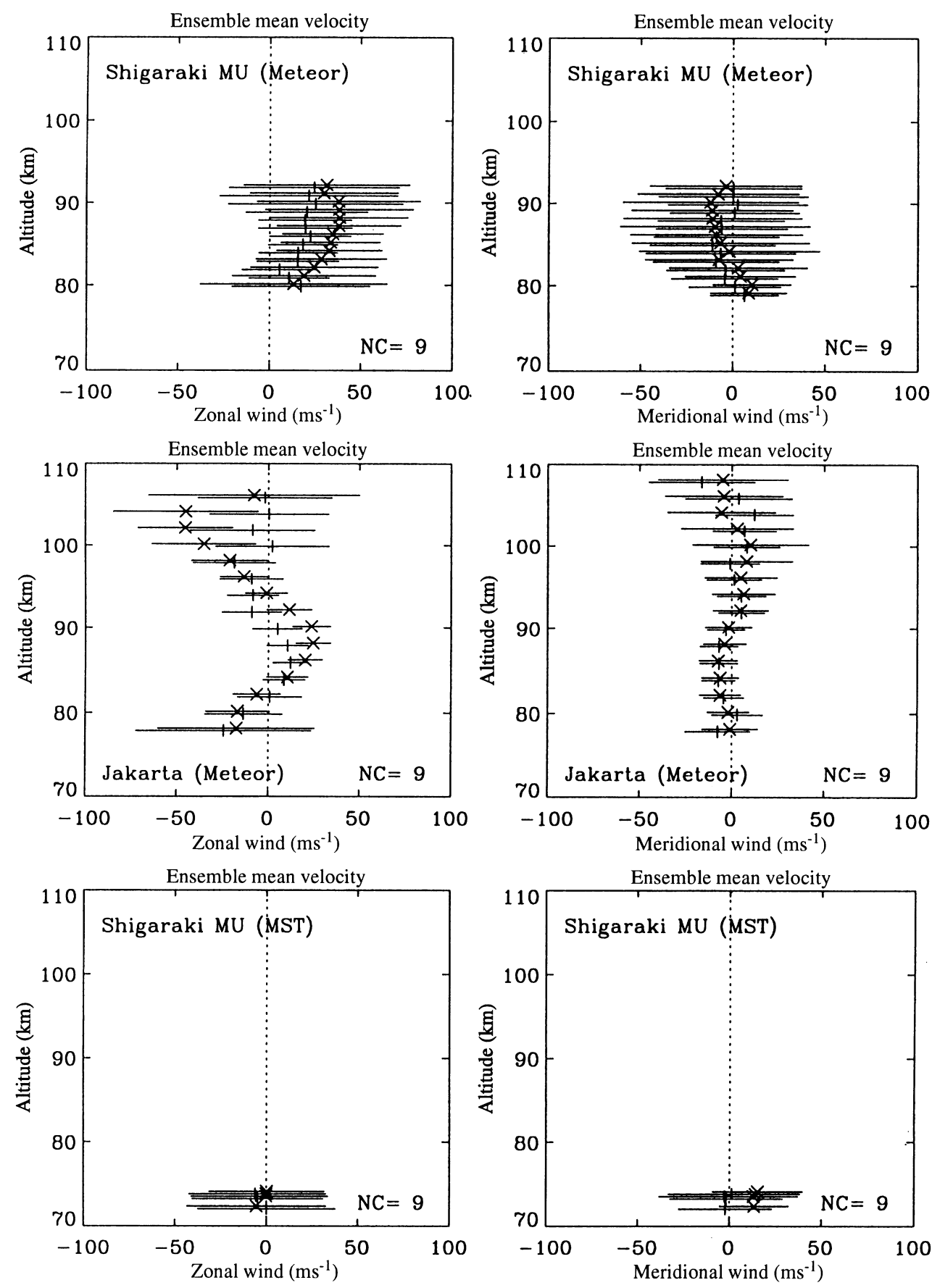

Fig. 4. Vertical profiles of the ensemble mean wind velocity components simultaneously observed by HRDI (crosses) and radars (pluses). Horizontal bars are the confidence interval of $99 \%$. To avoid overlap of bars, wind profiles are shifted $0.15 \mathrm{~km}$ upward for HRDI and $0.15 \mathrm{~km}$ downward for radars. Left: zonal wind, right: meridional wind

the chi-square tests. The results are summarized in the upper part of Table 2. With the significance level of 0.01 , it is concluded that the assumption of the normal distribution is not acceptable. It is thus necessary to perform some statistical tests that do not assume Gaussian distribution, namely nonparametric tests.

Among the tests available, we have performed two well-known ones: the sign test and Wilcoxen's rank sum test. The former simply counts the number of paired data that have a larger value in one group and smaller value in the other, irrespective of the magnitude of the difference. The results are compared with those values expected from a binomial distribution. The latter test uses the sum of the rank in the magnitude of the differences between paired samples. By these tests, one can examine the hypothesis that the median of the two samples are statistically different. The results are summarized in Table 3 . The differences are nonsignificant at the 0.01 level for most cases. However, in the case of the MU radar-meteor mode, significant differences are detected (HRDI gives larger wind speeds) at the altitude of 88 and $89 \mathrm{~km}$ by both tests and at $84 \mathrm{~km}$ by the sign test, although the judgment lies just on the border of the critical region. For the Jakarta meteor radar, the differences are significant at $104-\mathrm{km}$ altitude. None of the differences are significant for the comparisons with the MU radar MST mode operation. These results suggest that HRDI may overestimate wind speeds at 

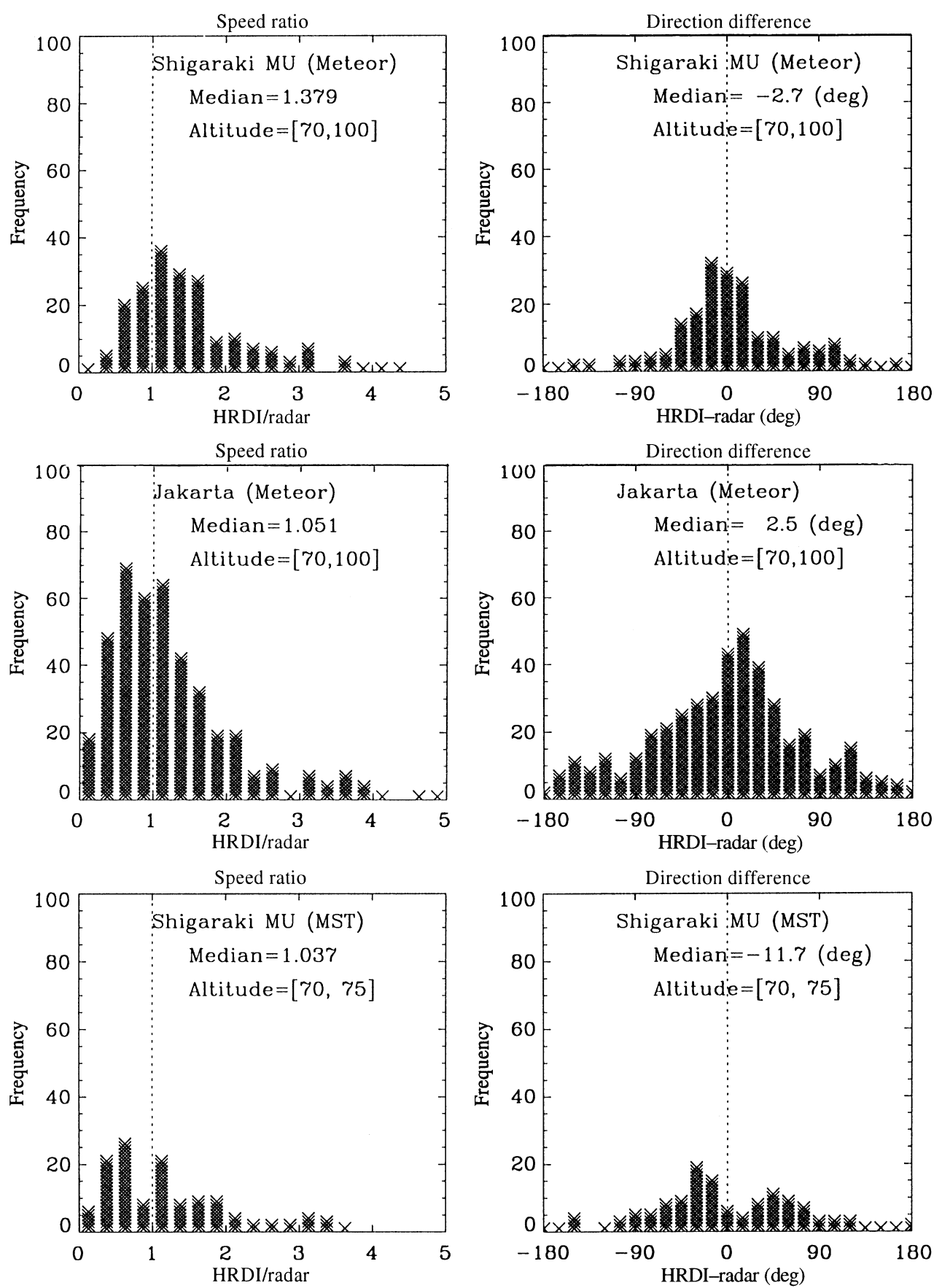

Fig. 5. Histograms of the speed ratio (HRDI/radar) and the direction difference (HRDI - radar). The altitude of the samples ranges from 70 to $100 \mathrm{~km}$ for meteor radars and from 70 to $75 \mathrm{~km}$ for MST mode MU radar such altitude and locations. It is noteworthy, however, that we have only ten coincidences for all of these cases.

Finally we apply a traditional $t$-test that assumes the normal distribution for the population to the windspeed data. Before applying the method, however, we need to suppress the wing at the higher side of the windspeed distribution function, so that the assumption of the normal distribution is met. This is done by taking the square root of the wind speed (lower panel of Fig. 7). By looking at the chi-square values shown in the lower part of Table 2, we can see that this procedure successfully transforms the distribution into one that is acceptable as a normal distribution. It should be noted, however, that this transformation is nonlinear.
The left-hand column of Fig. 8 shows the vertical profiles of the ensemble mean wind speed simultaneously observed by HRDI and the meteor radars after the square-root of the wind speed is taken. The error bars correspond to the $99 \%$ confidence interval of the square root of the population wind speed. The right-hand column of Fig. 8 illustrates the vertical profiles of the wind direction differences (HRDI - radar). For both the MU radar (meteor mode) and the Jakarta meteor radar, the confidence intervals of the population mean wind speed overlap for each altitude. This provides statistical evidence that the wind speed with square-root transformation does not show a statistically significant difference between HRDI and the meteor radars. There 

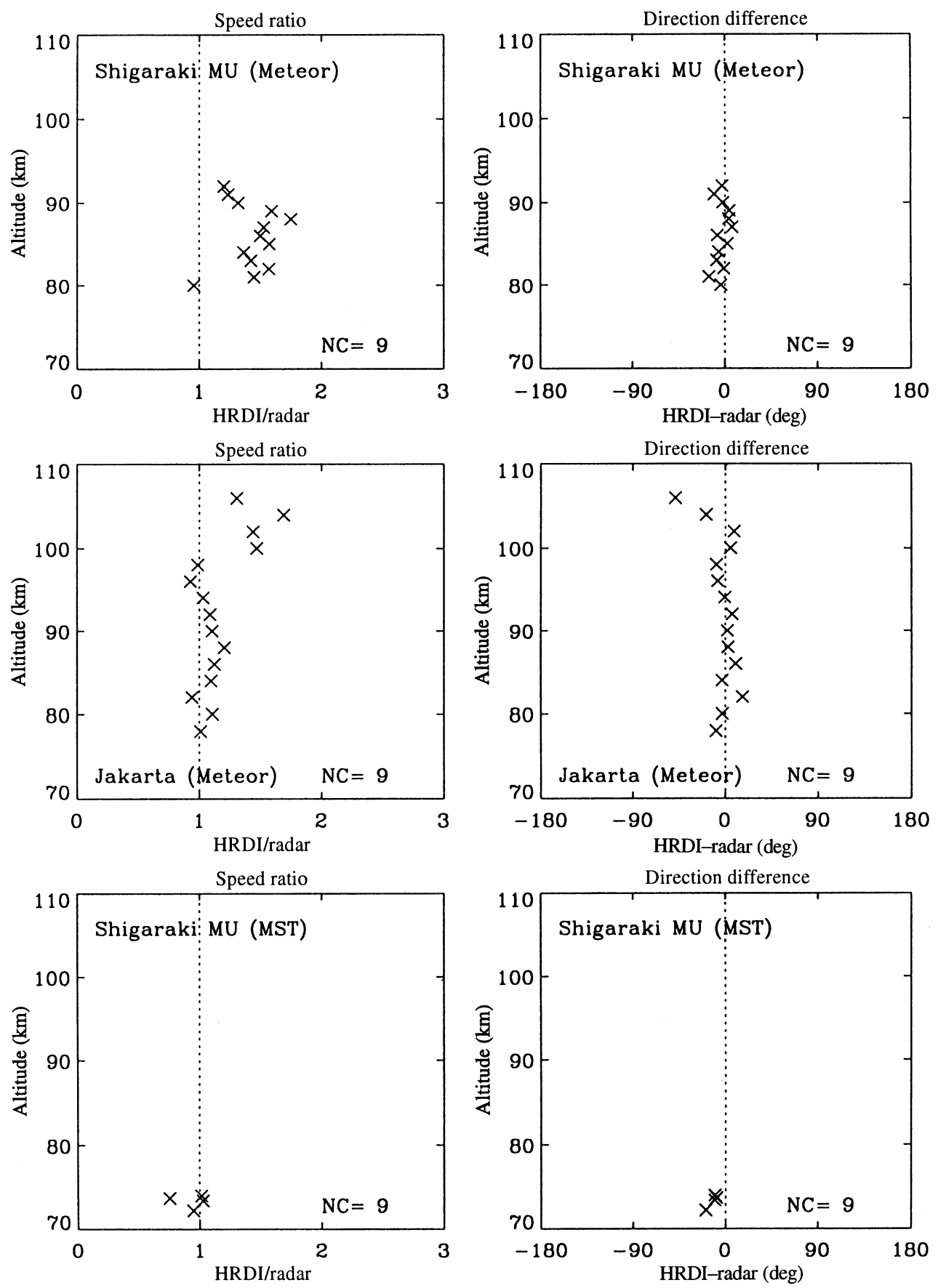

Fig. 6. Vertical profiles of the median of the speed ratio (HRDI/radar) and the direction difference (HRDI - radar)

is no indication of a difference in the wind directions from the two techniques. Thus, there appears to be little evidence for the overestimation of the wind speed by HRDI when compared with meteor radars.

\section{Estimation of the precision}

The purpose of this section is to estimate the precision of the wind velocity component derived by HRDI and by the meteor radars. Before describing our method of analysis, it is useful to demonstrate the limitation of conventional statistics. The uncertainty of the observa- tion is usually expressed by variances. For the radar and HRDI data, it is given as follows:

$$
\begin{aligned}
\overline{\hat{f}_{i}^{\prime 2}} & =\overline{f_{i}^{\prime 2}}+\overline{\varepsilon_{i}^{\prime 2}} \\
& =\overline{f^{\prime 2}}+\sigma_{f}^{2},
\end{aligned}
$$

and

$$
\begin{aligned}
\overline{\hat{h}_{i}^{\prime 2}} & =\overline{h_{i}^{\prime 2}}+\overline{\eta_{i}^{\prime 2}} \\
& =\overline{h^{\prime 2}}+\sum_{k, m ; l} w_{k, l} w_{m, l} \tau_{|k-m|} \\
& =\overline{h^{\prime 2}}+\sigma_{h}^{2},
\end{aligned}
$$



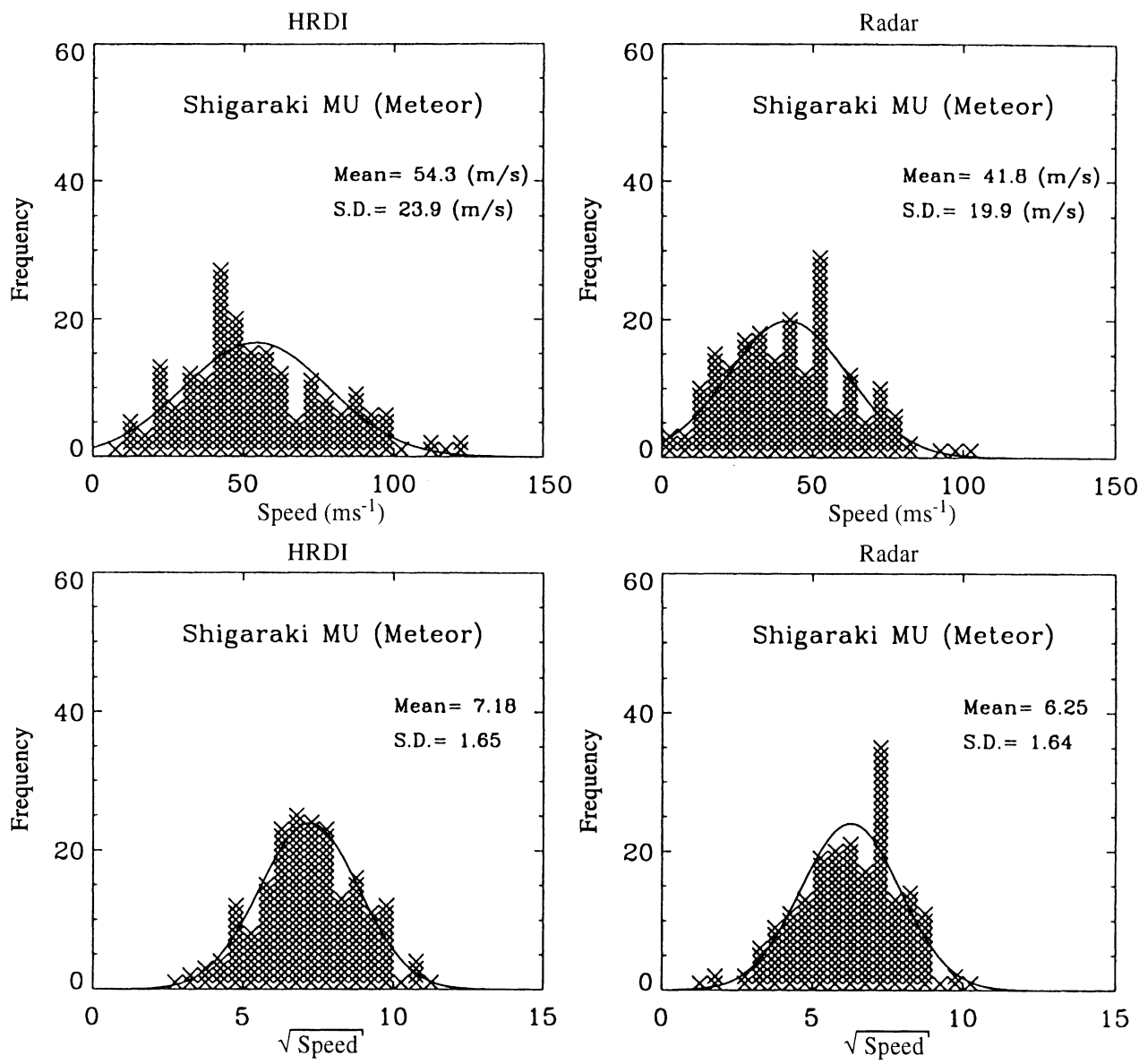

Fig. 7. Distributions of the speed and corresponding normal distribution functions for HRDI and radars. Top: raw values, bottom: values after taken by square root

Table 2. Goodness of fit in the normal distribution (significance level 0.01)

\begin{tabular}{llll}
\hline difference & $\chi^{2}$ & D.F. & lack of fitness \\
\hline MU/Meteor radar & 28.07 & 12 & significant \\
$\quad$ HRDI & 34.01 & 15 & significant \\
Jakarta radar & 58.67 & 15 & significant \\
HRDI & 59.20 & 19 & significant \\
$\sqrt{\text { speed difference }}$ & $\chi^{2}$ & D.F. & lack of fitness \\
MU/Meteor radar & 20.78 & 10 & not significant \\
$\quad$ HRDI & 9.01 & 10 & not significant \\
Jakarta radar & 10.05 & 12 & not significant \\
$\quad$ HRDI & 11.10 & 15 & not significant \\
\hline
\end{tabular}

where $\sigma_{h}^{2}$ is the variance of observational errors for HRDI processed data. These two quantities are the sum of the variances of the true value and the observational errors.

In validation studies, the variability of the observed values has often been expressed by the mean-square difference of the anomalies (e.g., Khattatov et al., 1996):

$$
\begin{aligned}
\overline{\left(\hat{f}_{i}^{\prime}-\hat{h}_{i}^{\prime}\right)^{2}} & =\overline{\left(\varepsilon_{i}^{\prime}-\eta_{i}^{\prime}\right)^{2}} \\
& =\sigma_{f}^{2}+\sum_{k, m ; l} w_{k, l} \mid w_{m, l} \tau_{|k-m|} \\
& =\sigma_{f}^{2}+\sigma_{h}^{2} .
\end{aligned}
$$

We can see that this is the sum of the variance of errors in both instruments. The values given by Eqs. 10, 11, and 12 are only a measure of some mixture of the physical variabilities and the observational uncertainties. In principle, the variance of the true values $\left(\overline{f^{\prime 2}} \equiv \overline{h^{\prime 2}}\right)$ and the observational errors $\left(\sigma_{f}^{2}\right.$ and $\left.\sigma_{h}^{2}\right)$ can be simultaneously solved from the three equations. However, this does not work well in a practical sense due mostly to the statistical fluctuations caused by the limited number of samples. We require some sophisticated statistics to separate observational errors from physical variabilities. In the present study we employ the structure function.

The structure function is defined by the mean square difference of the observed anomalies at pairs of locations (Gandin, 1963). It describes the three-dimensional structure of the field of variabilities in three-dimensional space. Traditionally, it is expressed as a two-dimensional function in a horizontal plane or as a one-dimensional function of the horizontal distance between the two locations (e.g., Alaka and Elvander, 1972; Hasebe, 1980, 1983). In this case, horizontal isotropy is assumed on a surface so that the directional dependency of the variabilities is neglected. For the network data with sparse horizontal distribution such as meteor radars, however, it is not possible to resolve the horizontal structure of the mean-square differences in this way. Our choice is, then, to take the separation between pairs of observations in the vertical direction for the profile data. 
Table 3. Results of nonparametric statistical tests for the difference of the wind speed derived by HRDI and radar observations; significance level is 0.01

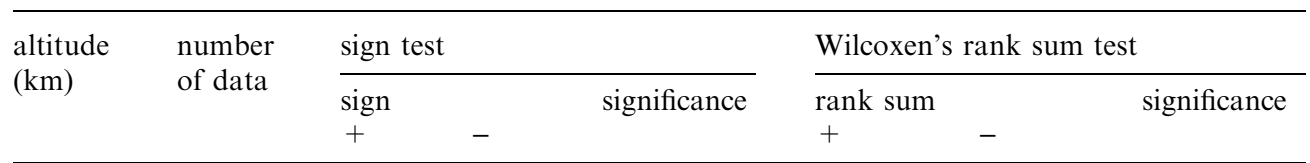

Shigaraki MU radar (meteor mode)

$\begin{array}{rr}80 & 9 \\ 81 & 10 \\ 82 & 10 \\ 83 & 9 \\ 84 & 10 \\ 85 & 11 \\ 86 & 11 \\ 87 & 10 \\ 88 & 10 \\ 89 & 10 \\ 90 & 9 \\ 91 & 9 \\ 92 & 9\end{array}$

$\begin{array}{ll}4 & 5 \\ 8 & 2 \\ 7 & 3 \\ 7 & 2 \\ 9 & 1 \\ 9 & 2 \\ 9 & 2 \\ 8 & 2 \\ 9 & 1 \\ 9 & 1 \\ 6 & 3 \\ 6 & 3 \\ 7 & 2\end{array}$

no
no
no
no
yes
no
no
no
yes
yes
no
no
no

Jakarta meteor radar

$\begin{array}{rrrrlrrr}78 & 9 & 5 & 4 & \text { no } & 19 & 26 & \text { no } \\ 80 & 20 & 11 & 9 & \text { no } & 89 & 121 & \text { no } \\ 82 & 28 & 12 & 16 & \text { no } & 195 & 211 & \text { no } \\ 84 & 43 & 27 & 16 & \text { no } & 548 & 398 & \text { no } \\ 86 & 47 & 27 & 20 & \text { no } & 658 & 470 & \text { no } \\ 88 & 51 & 28 & 23 & \text { no } & 774 & 552 & \text { no } \\ 90 & 53 & 33 & 20 & \text { no } & 887 & 544 & \text { no } \\ 92 & 43 & 22 & 21 & \text { no } & 476 & 470 & \text { no } \\ 94 & 44 & 22 & 22 & \text { no } & 487 & 503 & \text { no } \\ 96 & 38 & 18 & 20 & \text { no } & 367 & 374 & \text { no } \\ 98 & 26 & 12 & 14 & \text { no } & 194 & 157 & \text { no } \\ 100 & 18 & 11 & 7 & \text { no } & 124 & 47 & \text { no } \\ 102 & 16 & 11 & 5 & \text { no } & 100 & 36 & \text { no } \\ 104 & 10 & 9 & 1 & \text { yes } & 54 & 1 & \text { yes } \\ 106 & 9 & 7 & 2 & \text { no } & 37 & 8 & \text { no }\end{array}$

Shigaraki MU radar (MST mode)

\begin{tabular}{lllllllll}
72.2 & 9 & 4 & 5 & no & 20 & 25 & no \\
73.4 & 9 & 5 & 4 & no & 24 & 21 & no \\
73.7 & 9 & 4 & 5 & no & 19 & 26 & no \\
74.0 & 9 & 5 & 4 & no & 22 & 23 & no \\
\hline
\end{tabular}

In the case of the radar and HRDI data characterized in Sect. 3, the structure functions will reduce to the following form:

\section{Radar vs. Radar}

$$
\begin{aligned}
\hat{b}_{i j} & =\overline{\left(\hat{f}_{i}^{\prime}-\hat{f}_{j}^{\prime}\right)^{2}} \\
& =\overline{\left(f_{i}^{\prime}-f_{j}^{\prime}\right)^{2}}+\overline{\left(\varepsilon_{i}^{\prime}-\varepsilon_{j}^{\prime}\right)^{2}} \\
& =b_{i j}+\overline{\varepsilon_{i}^{\prime 2}}+\overline{\varepsilon_{j}^{\prime 2}} \\
& =b_{i j}+2 \sigma_{f}^{2} .
\end{aligned}
$$

\section{HRDI vs. Radar}

$$
\begin{aligned}
\hat{b}_{i j} & =\overline{\left(\hat{f}_{i}^{\prime}-\hat{h}_{j}^{\prime}\right)^{2}} \\
& =b_{i j}+\overline{\varepsilon_{i}^{\prime 2}}+\overline{\eta_{j}^{\prime 2}} \\
& =b_{i j}+\sigma_{f}^{2}+\sigma_{h}^{2} .
\end{aligned}
$$

\section{HRDI vs. HRDI}

$$
\begin{aligned}
\hat{b}_{i j} & =\overline{\left(\hat{h}_{i}^{\prime}-\hat{h}_{j}^{\prime}\right)^{2}} \\
& =b_{i j}+\overline{\eta_{i}^{\prime 2}}+\overline{\eta_{j}^{\prime 2}}-2 \overline{\eta_{i}^{\prime} \eta_{j}^{\prime}} \\
& =b_{i j}+2 \sum_{k, m ; l} w_{k, l} w_{m, l}\left(\tau_{|k-m|}-\tau_{|i-j+k-m|}\right) .
\end{aligned}
$$

Because $b_{i j}$ is the mean-square difference of the true values between the altitudes $i$ and $j$, it should tend to zero when the altitude difference between the two levels, $\rho_{i j}$, tends to zero. Thus we can readily see that

1. Radar vs. Radar

$$
\hat{b}_{i j} \longrightarrow 2 \sigma_{f}^{2} \quad\left(\rho_{i j} \longrightarrow 0\right) .
$$

2. HRDI vs. Radar

$$
\hat{b}_{i j} \longrightarrow \sigma_{f}^{2}+\sigma_{h}^{2} \quad\left(\rho_{i j} \longrightarrow 0\right) \text {. }
$$



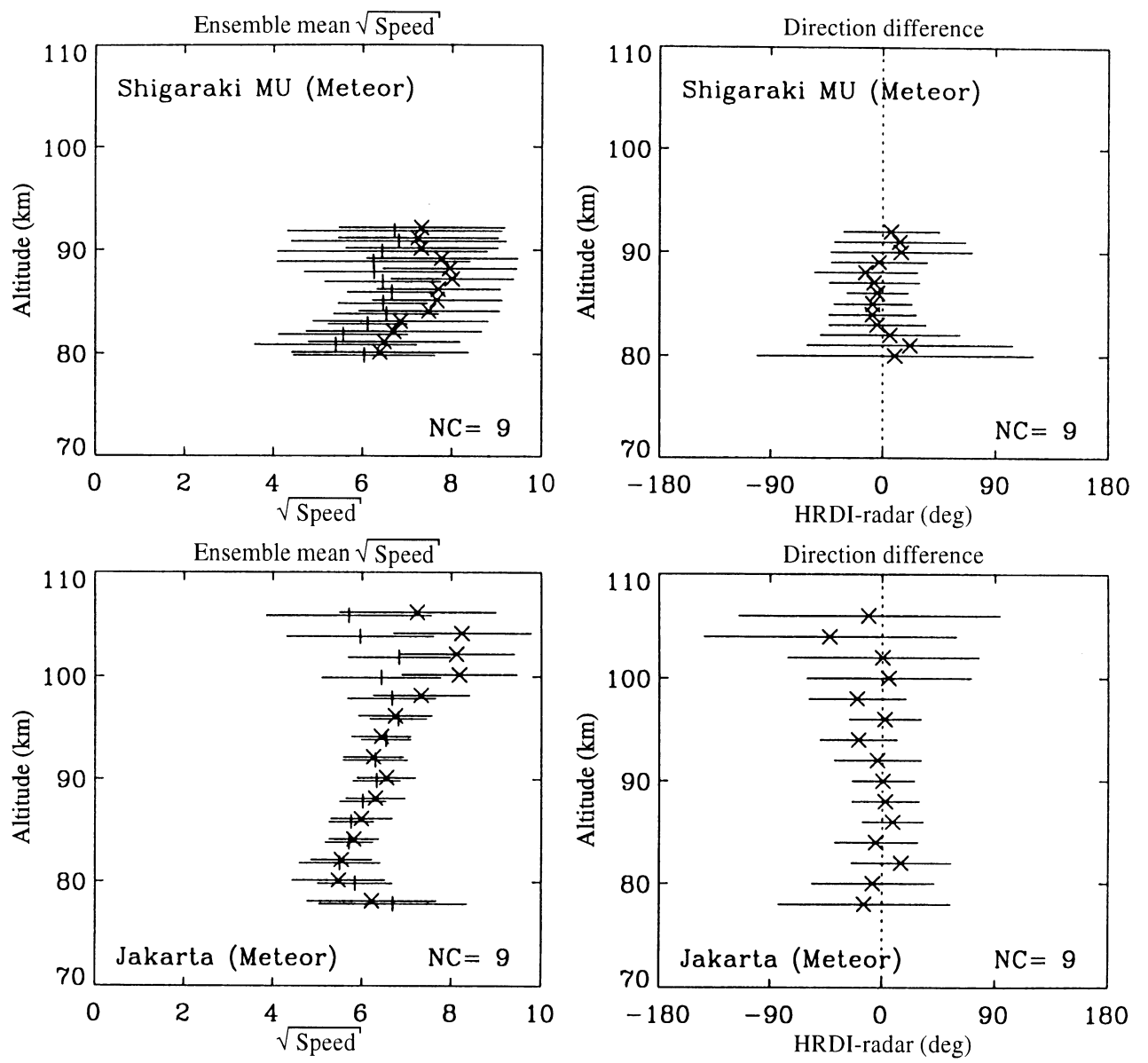

Fig. 8. Vertical profiles of left: the ensemble mean wind speed (taken by the square root) simultaneously observed by HRDI (crosses) and radars (pluses), and right: the ensemble mean wind direction difference. Horizontal bars are the confidence interval of $99 \%$. To avoid overlap of bars, wind speeds are shifted $0.15 \mathrm{~km}$ upward for HRDI and $0.15 \mathrm{~km}$ downward for radars

For the case of the HRDI vs. HRDI comparison, the limit depends on the functional form of the correlation function of the HRDI raw data, $\tau_{|i-j|}$. Considering the vertical resolution of HRDI, $\tau_{|i-j|}$ should be a continuous function of vertical separation even in the highly turbulent atmosphere. In this case, $\hat{b}_{i j}$ will tend to zero as $\rho_{i j}$ vanishes. Even when the separation is taken to be discrete, the situation is also true if $\tau_{|i-j|}$ is changing slowly as a function of $|i-j|$ as a result of sequential estimations. Thus, the limit of $\hat{b}_{i j}$ for HRDI vs. HRDI will be close to zero and provide practically no information. Therefore, we will not use those values derived from HRDI vs. HRDI comparisons. This situation does not apply for the radar data; the instrumental errors can be considered as independent (not correlated between each other) in the vertical direction. This is because the meteor wind profiles are composed of the wind velocities independently calculated at each altitude bin after geographical locations of the meteor trails are determined. The independence of observational errors will be almost guaranteed for the MST mode due to the time-split of the return echo.

Examples of the structure functions are shown in Fig. 9 , where the magnitude of the structure functions are plotted on the abscissa while the altitude is on the ordinate. Here the reference altitude is $90 \mathrm{~km}$; the logarithmic values of the structure functions calculated between $90 \mathrm{~km}$ and altitude $z$ are denoted by crosses at altitude $z$. The limit of $\hat{b}_{i j}$ as $\rho_{i j}$ approaches zero is calculated as the mean of the two values that specify the intersection of two least-square fits, one above the reference altitude and the other below it. Considering the vertical scale of the structure function, only three points for each side are used in this fitting procedure. To avoid possible correlations between the observational errors at the point of interest and the reference altitude, the nearest neighbors both below and above it are excluded for the radar vs. radar combinations.

The results are summarized in the left-hand column of Table 4. As will be discussed, these values may be used to examine the statistical significance of the wind field obtained by the averaging of some observed profiles. The uncertainty of the derived field is expressed by the confidence interval of the observed wind field. It can be reduced, in principle, by taking the ensemble mean of the samples. This is based on the fact that the magnitude of random errors will be proportional to $1 / \sqrt{N}$, where $N$ is the number of independent observations in the averaging. The estimated precision for HRDI (approximately $20 \mathrm{~m} \mathrm{~s}^{-1}$ ) implies that it can provide the wind velocities with a confidence interval of about $5 \mathrm{~m} \mathrm{~s}^{-1}$ if $15-20$ independent observations are superposed. This estimate can be used to examine the statistical significance of the diurnal tide, for example, derived from HRDI measurements. Morton et al. (1993) and Hays et al. (1994) obtained diurnal wind amplitudes of much more than $5 \mathrm{~m} \mathrm{~s}^{-1}$ (maximum of about $70 \mathrm{~m} \mathrm{~s}^{-1}$ according to Hays et al., 1994) by superposing the 

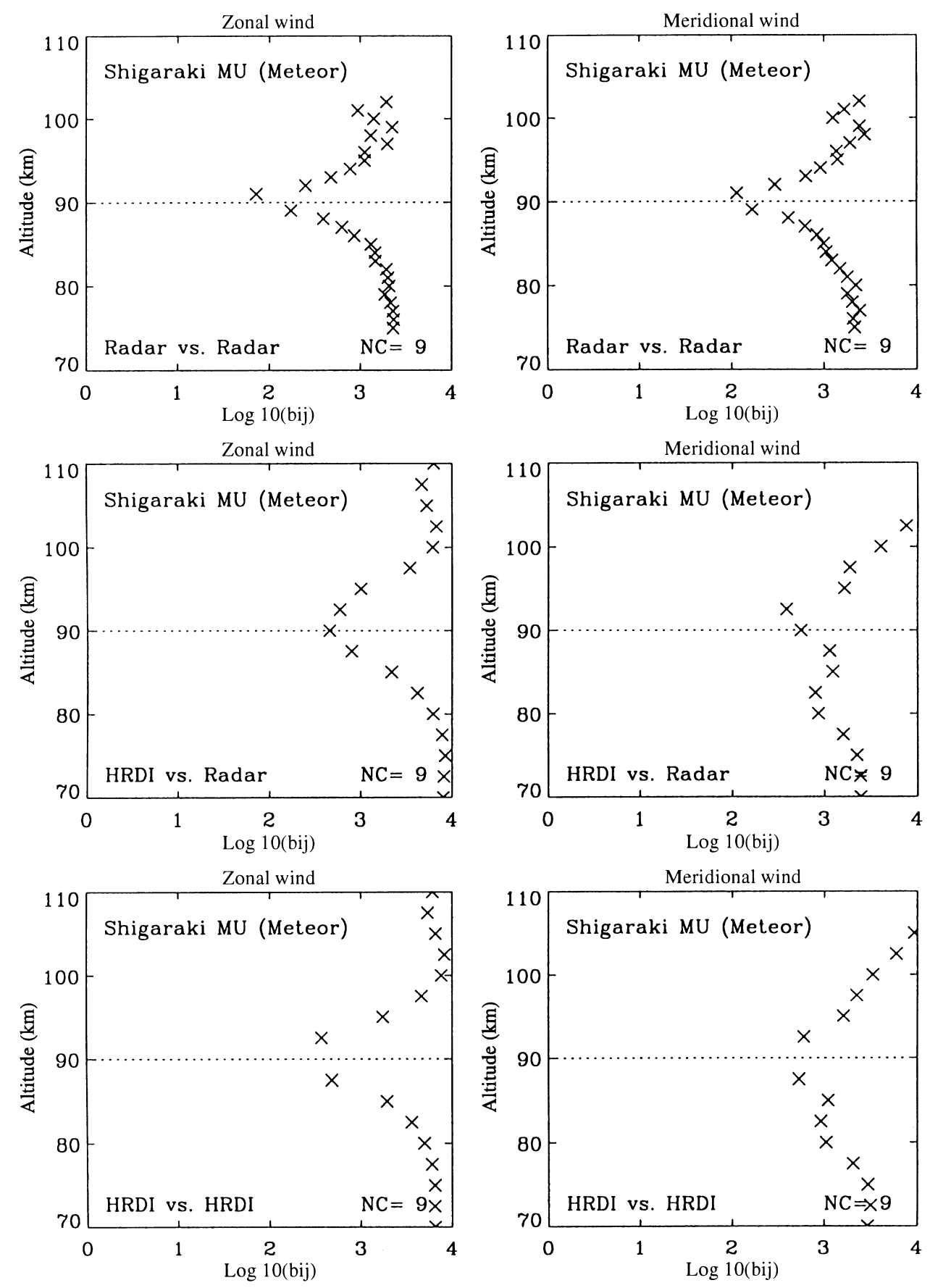

Fig. 9.

HRDI winds sorted according to local time. Thus the present result provides a statistical foundation that helps to confirm the tidal wind component estimated from HRDI data previously.

We can see that the precision is much better in the MU meteor mode than in the Jakarta meteor radar, due probably to the higher power of the transmitter, better antenna configurations, and the improved signal processing unit in the MU radar. One may obtain the impression that the HRDI winds are less reliable than both radars. As mentioned in Sect. 1, however, a simple comparison of the precision between HRDI and radars is not meaningful. The great strength of HRDI relative to ground-based systems is its truly global view of planetary-scale waves. In addition, radars need time integration on the order of an hour to achieve the required data quality, while HRDI can obtain a series of profiles by combining measurements separated by $9 \mathrm{~min}$. There is a trade-off between the required observational time and the achieved precision. In order to study the "efficiency" of the observational technique, the values $\sigma \times \sqrt{T}$ are also shown in Table 4 , where $T$ is the time-scale of the observation. The precision will be inversely proportional to $\sqrt{T}$ if $T$ can be interpreted as a measure of the number of independent measurements used to obtain a single profile. Then the efficiency of the 

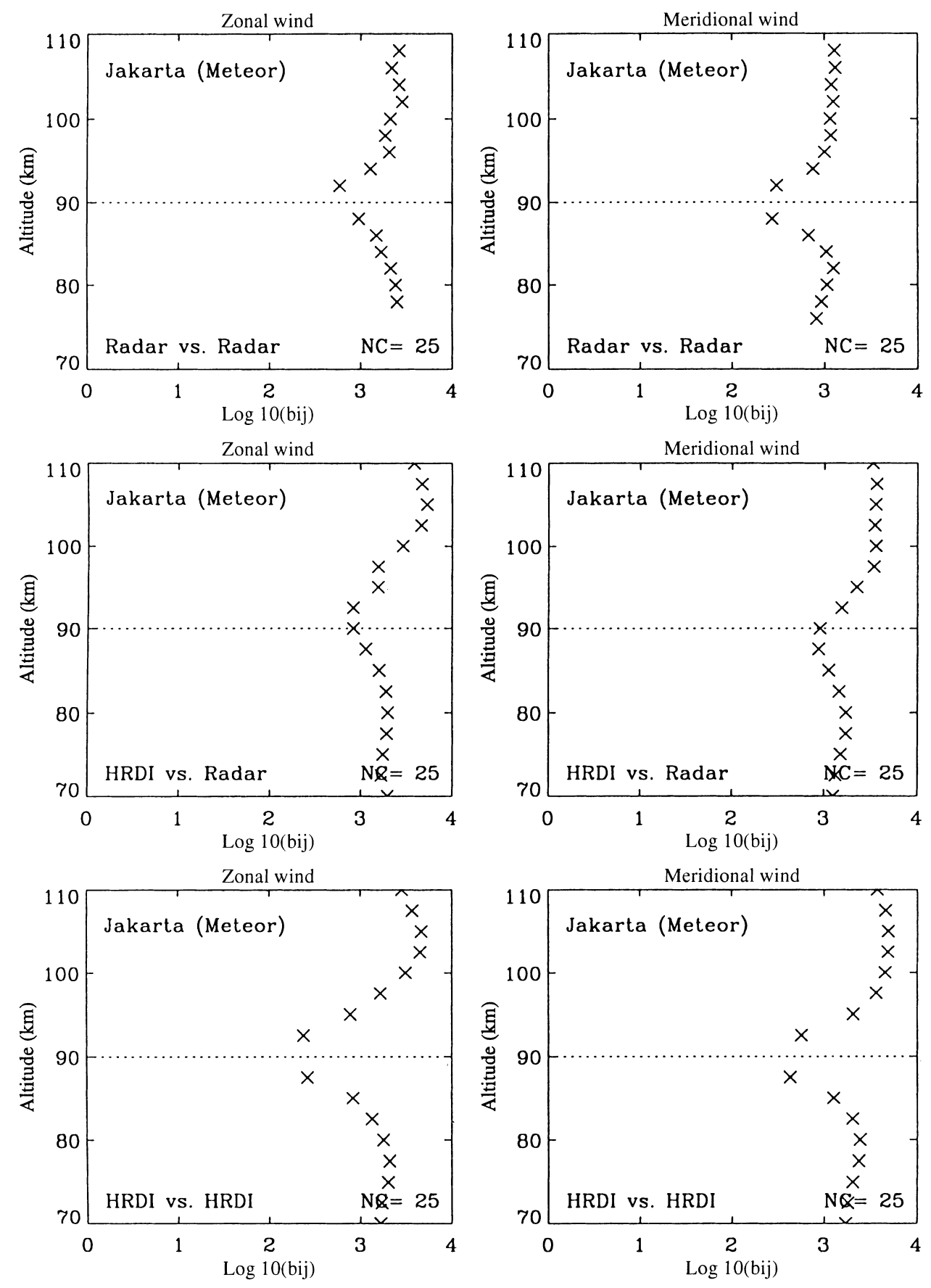

Fig. 9. Examples of the structure functions obtained by the combination of radar vs. radar, HRDI vs. radar, and HRDI vs. HRDI for Shigaraki MU radar (meteor mode) and Jakarta meteor radar both at $90-\mathrm{km}$ altitude

Table 4. Estimated precision of HRDI and meteor-radar wind velocities at $90-\mathrm{km}$ altitude. For comparative purposes, the efficiency of the observation technique defined by the multiple of the precision and square root of the representative time-scale is also shown; see text for details

\begin{tabular}{|c|c|c|c|c|}
\hline $90 \mathrm{~km}$ & $\begin{array}{l}\text { precision } \\
\sigma \\
\left(\mathrm{m} \mathrm{s}^{-1}\right)\end{array}$ & $\begin{array}{l}\text { time-scale } \\
T \\
\text { (min) }\end{array}$ & $\begin{array}{l}\text { spat.scale } \\
L \\
(\mathrm{~km})\end{array}$ & $\begin{array}{l}\text { efficiency } \\
\sigma \times \sqrt{T} \\
\left(\mathrm{~m} \mathrm{~s}^{-1} \min ^{1 / 2}\right)\end{array}$ \\
\hline \multicolumn{5}{|l|}{ Radars } \\
\hline Shigaraki & 6 & 60 & 100 & 46 \\
\hline Jakarta & 15 & 60 & 200 & 116 \\
\hline HRDI & 20 & 9 & 500 & 60 \\
\hline
\end{tabular}

observational technique may be measured by the magnitude of the precision multiplied by $\sqrt{T}$. In this sense, the HRDI wind measurements in the mesosphere and lower thermosphere prove to be comparably efficient to the meteor radars.

\section{Discussion}

As is expected from the mathematical formula, the distribution functions for the wind speed observed by HRDI and the meteor radars are found to be significantly different from the normal distribution (Sect. 4). This leads us to apply nonparametric tests that do not 
rely on the assumption of a normal distribution. These tests are robust in that the results are affected little by factors that are not relevant to our validation studies. On the other hand, they are usually insensitive in detecting statistical differences between the samples. Before concluding our analysis, therefore, we have also applied conventional statistical tests that assume the normal distribution for the population. We have applied the square-root transformation in an attempt to avoid the problems associated with the inappropriate assumption of a normal distribution for the population. Because this transformation is non-linear, however, the result of the tests does not guarantee that the wind speed itself is not statistically different, although the square root of the wind speed is not statistically different. The present distribution functions are similar to a Gamma distribution that has a relatively long tail in the wing of higher values. As far as the authors are aware, the theory of statistical tests on the difference of the mean value of the population is not known if the population is specified by the Gamma distribution or something applicable to the actual wind-speed distribution. The accuracy of the HRDI wind relative to the meteor radars should be re-examined when such a theory becomes available.

Similar estimation of the precision has been performed using the wind data observed by the MF radars located at Adelaide, Christmas Island, and Saskatoon. The resultant structure functions give estimates for the precision of the MF radars of several meters per second, while that for HRDI is about $30 \mathrm{~m} \mathrm{~s}^{-1}$, a somewhat larger value than that obtained by using meteor radars. It is unlikely that the precision of the HRDI winds is worse for the locations specifically above the MF radars. Possible reasons for this disagreement may include:

1. A difference in the version and the level of processing of the HRDI data used in the analysis.

2. The existence of systematic errors such as those having a correlation with the observing quantity (e.g.,, $\left.\bar{f}_{i}^{\prime} \varepsilon_{i}^{\prime} \neq 0\right)$ and/or those being correlated between themselves (e.g., $\overline{\varepsilon_{i}^{\prime} \varepsilon_{j}^{\prime}} \neq 0$ ).

The systematic error problem mentioned may be relevant to the MF radars due to the oversampling procedure applied to provide the data at $2-\mathrm{km}$ altitude intervals. In the latter case, because the term $\overline{\varepsilon_{i}^{\prime} \varepsilon_{j}^{\prime}}$ would not vanish but take some positive value in Eq. 13, the observational errors for MF radars could be underestimated, while those for HRDI be overestimated, thus providing a qualitatively consistent interpretation with those results obtained by meteor radars. Extended analyses are required to attain a consolidated view on the observational errors among HRDI, meteor radars, and $\mathrm{MF}$ radars.

In this study, we obtained two equations for two unknowns. This situation is favorable in the sense that we can reach a unique solution. However, it could be a disadvantage in that we are not aware of the inconsistency of the results even when some assumptions do not hold in reality. Without some additional information, it is generally difficult to confirm the validity of the assumptions. It may be helpful, however, to consider how the precision depends on the temporal scale of measurements. That is, within a regime where physical variabilities are approximately uniform, we would expect some improvement in the precision of the radars as we lengthen the time integration. The information on the dependency of observational errors on the length of time averaging will also be useful in later application of the radar data in meteorological research.

\section{Concluding remarks}

The accuracy relative to the ground-based radars and the precision of the MLT wind measurements of HRDI on board UARS are estimated by using the meteor radars. The accuracy of HRDI winds relative to meteor radars is found to be high, in that overall differences in the wind velocities are not statistically significant at the 0.01 level between HRDI and the meteor radars. Some exceptions noticed at the altitude around $88 \mathrm{~km}$ may be considered as the statistical fluctuations due to the limited number of coincidences currently available. This may imply that the wind-speed difference between HRDI and MF radars reported previously could be due to underestimation by the MF radars. Further improvement of the tests will be possible if a new theory more suitable for the actual wind-speed distributions becomes available. The application of the structure functions reveals that the precision of the HRDI single wind profile is about $20 \mathrm{~m} \mathrm{~s}^{-1}$, while that of a meteor radar with 1 -h integration is about $6 \mathrm{~m} \mathrm{~s}^{-1}$ for Shigaraki and $15 \mathrm{~m} \mathrm{~s}^{-1}$ for the Jakarta meteor radar. These conclusions are still valid for the current version 11 of HRDI data. The method described in this study is applicable to the validation of other profile observations provided some proper correlative data exist.

Acknowledgements. A part of this work was done while FH was visiting at the Institute for Terrestrial and Planetary Atmospheres, State University of New York at Stony Brook. He wishes to express hearty gratitude to Prof. Marvin A. Geller of the Institute for giving him an opportunity to do research on this study and continuing encouragement throughout this work. We would like to express our thanks to Dr. Robert A. Vincent and Prof. Alan H. Manson for providing the MF radar data. FH is also grateful to Y-C. Chi for assistance in preparation and handling of the data during his stay in Stony Brook. The MU radar is operated by Radio Atmospheric Science Center, Kyoto University. The Jakarta meteor radar is operated under a cooperation between BPPT, Indonesia, LAPAN, Indonesia, and RASC, Kyoto University.

Topical Editor F. Vial thanks J. Forbes and J. Röttger for their help in evaluating this paper.

\section{References}

Abreu, V. J., A. Bucholtz, P. B. Hays, D. A. Ortland, W. R. Skinner, and J.-H. Yee, Absorption and emission line shapes in the $\mathrm{O}_{2}$ atmospheric bands: theoretical model and limb viewing simulations, Appl. Opt., 28, 2128-2137, 1989.

Alaka, M. A., and R. C. Elvander, Optimum interpolation from observations of mixed quality, Mon. Weather Rev., 100, 612624, 1972. 
Baily, P. L., and J. C. Gille, Inversion of limb radiance measurements: an operational algorithm, J. Geophys. Res., 91, 27572774, 1986.

Burrage, M. D., W. R. Skinner, A. R. Marshall, P. B. Hays, R. S. Lieberman, S. J. Franke, D. A. Gell, D. A. Ortland, Y. T. Morton, F. J. Schmidlin, R. A. Vincent, and D. L. Wu, Comparison of HRDI wind measurements with radar and rocket observations, Geophys. Res. Lett., 20, 1259-1262, 1993.

Burrage, M. D., N. Arvin, W. R. Skinner, and P. B. Hays, Observations of the $\mathrm{O}_{2}$ atmospheric band nightglow by the high-resolution Doppler imager, J. Geophys. Res., 99, $15017-$ 15 023, 1994.

Burrage, M. D., W. R. Skinner, D. A. Gell, P. B. Hays, A. R. Marshall, D. A. Ortland, A. H. Manson, S. J. Franke, D. C. Fritts, P. Hoffman, C. McLandress, R. Niciejewski, F. J. Schmidlin, G. G. Shepherd, W. Singer, T. Tsuda, and R. A. Vincent, Validation of mesosphere and lower thermosphere winds from the high-resolution Doppler Imager on UARS, $J$. Geophys. Res., 101, 10 365-10 392, 1996.

Burrage, M. D., W. R. Skinner, and P. B. Hays, Intercalibration of the HRDI and WINDII wind measurement techniques, Ann. Geophysicae, this issue, 1997.

Gandin, L. S., Objective Analysis of Meteorological Fields, Gidrometeorologicheskoe Izdatel'stvo, Leningrad, translated from Russia, Israel program for scientific translations, Jerusalem, 1963.

Gille, J. C., and W. Grose (Eds), Temperature and constituents, Report of the 1994 Upper Atmosphere Research Satellite Workshop III, NASA Reference Publication, 1994.

Hasebe, F., A global analysis of the fluctuation of total ozone. I. Application of the optimum interpolation to the network data with random and systematic errors, J. Meteorol. Soc. Japan, 58, 95-103, 1980.

Hasebe, F., Interannual variations of global total ozone revealed from Nimbus 4 BUV and ground-based observations $J$. Geophys. Res., 88, 6819-6834, 1983.

Hays, P. B., V. J. Abreu, M. E. Dobbs, D. A. Gell, H. J. Grassl, and W. R. Skinner, The high-resolution Doppler Imager on the Upper Atmosphere Research Satellite, J. Geophys. Res., 98, 10 713-10 723, 1993.

Hays, P. B., D. L. Wu, and the HRDI Science Team. Observations of the diurnal tide from space, J. Atmos. Sci., 51, 3077-3093, 1994.

Igarashi, K., I. Nishimuta, Y. Murayama, T. Tsuda, T. Nakamura, and $\mathrm{M}$. Tsutsumi, Comparison of wind measurements between
Yamagawa MF radar and the MU radar, Geophys. Res. Lett., 23, 3341-3344, 1996.

Khattatov, B. V., M. A. Geller, V. A. Yudin, P. B. Hays, W. R. Skinner, M. D. Burrage, S. J. Franke, D. C. Fritts, J. R. Isler, A. H. Manson, C. E. Meek, R. McMurray, W. Singer, P. Hoffmann, and R. A. Vincent, Dynamics of the mesosphere and lower thermosphere as seen by MF radars and by the highresolution Doppler imager/UARS, J. Geophys. Res., 101, 10 393-10 404, 1996.

Morton, Y. T., R. S. Lieberman, P. B. Hays, D. A. Ortland, A. R. Marshall, D. Wu, W. R. Skinner, M. D. Burrage, D. A. Gell, and J.-H. Yee, Global mesospheric tidal winds observed by the High Resolution Doppler Imager on board the Upper Atmosphere Research Satellite, Geophys. Res. Lett., 20, 1263-1266, 1993.

Nakamura, T., T. Tsuda, M. Tsutsumi, K. Kita, T. Uehara, S. Kato, and S. Fukao, Meteor wind observations with the MU radar, Radio Sci., 26, 857-869, 1991.

Ortland, D. A., P. B. Hays, W. R. Skinner, M. D. Burrage, A. R. Marshall, and D. A. Gell. A A sequential estimation technique for recovering atmospheric data from orbiting satellites, The Upper Mesosphere and Lower Thermosphere, Geophysical Monograph Series, Vol. 87, edited by R. M. Johnson and T. L. Killeen, AGU, Washington, DC, pp. 329-337, 1995

Ortland, D. A., W. R. Skinner, P. B. Hays, M. D. Burrage, R. S. Lieberman, A. R. Marshall, and D. A. Gell, Measurements of stratospheric winds by the high-resolution Doppler imager, $J$. Geophys. Res., 101, 10 351-10 363, 1996.

Reber, C. A., C. E. Trevathan, R. J. McNeal, and M. R. Luther, The Upper Atmosphere Research Satellite (UARS) mission, $J$. Geophys. Res., 98, 10 643-10 647, 1993.

Rodgers, C. D., Retrieval of atmospheric temperature and composition from remote measurements of thermal radiation, Rev. Geophys. Space Phys., 14, 609-624, 1976.

Tsuda, T., S. Kato, T. Yokoi, T. Inoue, M. Yamamoto, T. E. VanZandt, S. Fukao, and T. Sato, Gravity waves in the mesosphere observed with the MU radar, Radio Sci., 26, 1005-1018, 1990.

Tsuda, T., S. Fukao, M. Yamamoto, T. Nakamura, M. D. Yamanaka, T. Adachi, H. Hashiguchi, N. Fujioka, M. Tsutsumi, S. Kato, S. W. B. Harijono, T. Sribimawati, B. P. Sitorus, R. B. Yahya, M. Karmini, F. Renggono, B. L. Parapat, W. Djojonegoro, P. Mardio, N. Adikusumah, H. T. Endi, and H. Wiryosumarto, A preliminary report on observations of equatorial atmosphere dynamics in Indonesia with radars and radiosondes, J. Meteorol. Soc. Japan, 73, 393-406, 1995. 